has outpaced theory and interpretation, and once this is remedied, and the runners in the race get their second wind, more exciting progress will be made.

Fortunately 'steam-radio' (that is, free radical) vinyl polymerizations continue to be studied, with the work perhaps best described as being in the consolidation state. Valuable reviews of the applications to polymer studies of radioactive labelling and electron spin resonance were provided by J. C. Bevington and D. H. Whiffen, respectively (both of Birmingham). The industrially very important process of polymerization in heterogeneous media attracted some attention.

A session was held on the polymerization of caprolactam, at which all the papers were given by workers on the Continent.

One section was devoted to the discussion of natural polymers and model substances. W. Kuhn (of Basle) gave a fascinating lecture on the production of mechanical energy by macromolecular systems. Current interest in polypeptides was reflected by lectures by T. Wieland (of Frankfurt) on the organic chemistry of the formation of peptide links and $\mathrm{C} . \mathrm{H}$. Bamford (of Maidenhead) on synthetic polypeptides. In these two lectures, a fascinating contrast between the ingenuities of the organic and the physical chemist was displayed. Close as are these two studies to the processes of life itself, some studies that were reported on nucleic acids, cancer, and enzyme action were even closer, and demonstrated the extensive range of topics to which polymer science has a major contribution to make.

Starch and cellulosic chemistry was also treated in several contributions and lectures by E. Husemann (of Freiburg) and H. Sihtola (of Helsinki). One interesting new discovery by $\varnothing$. Ellefsen (of Oslo) was the preparation of a new crystalline modification of cellulose. Only a few papers were given on rubber, including a review by W. F. Watson (of Shawbury) of recent work on the mechanochemical reactions of polymers.

A very interesting section was that on what might be termed the preparative chemistry of organic and inorganic polymers. A review of new condensation polymers was given by $\mathrm{H}$. Mark (of New York); this included an elegant demonstration of 'interfacial polycondensation', by means of which high-molecular weight polyamides are formed virtually instantaneously at room temperature. The happy term 'Instant Nylon' has been coined in the United States for this polymer. The application of classical organic reactions to vinyl polymers leads to many interesting new products, and progress in this field was summarized by G. J. Smets (of Louvain). Considerable interest is boing currently shown in inorganic, and organic/inorganic polymers, and this was reflected in numerous short papers as well as set lectures by E. Thilo (of Berlin), H. Deuel (of Zurich), H. Krebs (of Bonn) and S. Nitzsche (of Burghausen). Various unusual organic polycondensation reactions, and methods of forming cross-linked polymers and block copolymers, also received attention.

It will be obvious from the above, highly inade. quate, summary that there was scarcely an aspect of polymer science that did not receive attention. Whether this is the best programme for a conference is a matter for debate, as it can be argued that limitation of the subject-matter promotes a fuller and deeper discussion. There can be no doubt, however, that the Symposium once again fulfilled its main purpose of bringing together polymer scientists and promoting fertile interchanges of views.

Some of the main lectures have already appeared in Die Makromolekulare Chemie, and the remainder, together with the discussions, will appear in later issues.
L. VaLentine

\title{
INDUSTRY AND THE TECHNICAL COLLEGES IN BRITAIN
}

\begin{abstract}
$\mathrm{A}^{\mathrm{N}}$ $\mathrm{N}$ important paper on the relationship between industry and technical colleges was presented at a conference arranged by the Liverpool District of the Federation of British Industries at Chester on October 21. The speaker, Mr. L. S. Newton, of Pilkington Bros., Ltd., suggested that, despite the increased attention being paid by industry to the education and training of its personnel, there are three ways in which many firms are still not making a real contribution to the development of the educated man-power of Great Britain.

Many firms are still evading their responsibility for training young people and are content to recruit their craftsmen, technicians and technologists from other companies. Industry should accept the opportunity provided by the 'bulge' to analyse its requirements for the next ten to fifteen years to see how many young people it could now absorb to train for later years. Many firms also do not provide facilities for part-time release for study in the day-time-this applies not only to industry but also to professional and commercial undertakings. Industry frequently fails to discriminate between the branches of study, the facilities for commercial students remaining quite inadequate.
\end{abstract}

A feature of post-war development has been the remarkable rise in the number of students being released for sandwich courses. The number of students attending the technical colleges full-time or on a sandwich basis has risen tenfold in the past twenty years, between 80 and 90 thousand being in attendance at the moment. What the ultimate ratio should be has not yet become clear, but industry's support for sandwich courses is far from uniform and largely in the hands of the larger and more progressive companies.

Mr. Newton's most important contribution to the conference, however, was concerned with the ways in which closer co-operation between industry and the technical colleges could be achieved.

There are four main places where action could be taken to establish, maintain and foster relationships between the two bodies for their mutual benefit: (a) there should be a closer tie at the policy-making level; $(b)$ there should be a closer tie at the point at which the contents of syllabuses and courses are determined; (c) there should be a closer tie at the teaching level; and $(d)$ there should be a greater sharing of responsibility for the success of the student. 
Probably the most important contribution that industry can make is to participate in policy formulation for the organization and administration of technical colleges by serving on college governing bodies and departmental advisory committees. Some colleges are still governed by a committee which is a sub-committee of the local further education committee, which itself is a sub-committee of the education committee of the local authority. "Moreover, we view with increasing concern the growing intrusion of local political issues into the deliberation of some governing bodies which has a discouraging effect on industrial participation."

Industry must co-operate in the teaching of technical colleges partly by encouraging more of its qualified. young men and women to accept part-time teaching posts in the colleges and also by releasing, where nocessary, men of appropriate skill and knowledge to teach on a part-time day basis. Sandwich courses in particular need teachers with close and current contact with industrial problems; these are not always to be found-nor could they be fully and

\section{MODERN NETWORK THEORY}

$\mathrm{T}$ HE first phase in the development of network theory was opened by the work of Ohm in 1827 and may be regarded as being terminated, at the end of the nineteenth century, by the work of Heaviside. By this date the main concepts and methods of network analysis were established and aithough mathematicians more orthodox than Heaviside were yet to present operational methods in a different light, little other work of significance appeared between 1900 and 1922. The subsequent growth of network theory was greatly stimulated by the use of the notion of a complex frequency, a concept which, in its turn, grew out of the application of the theory of functions of a complex variable to those problems of time-variation in networks which had previously been treated by the methods of Heaviside.

With the introduction of more powerful mathematical tools it became possible, in the second and present phase in the growth of network theory, to treat the problems of realizability, synthesis, approximation and practical design, that is to say, which mathematical functions may be realized as network characteristics? How may networks having prescribed, realizable, characteristics be found? By what approximations may a desired physical response be most usefully and economically translated into a set of realizable mathematical functions? In what manner do the general mathematical processes of realization and synthesis require to be treated if the outcome is to be a practicable network using a comparatively small number of relatively cheap components?

These are some of the questions with which modern network theory is concerned, and to discuss them the Department of Electrical Engineering of the University of Birmingham organized an informal conference which took place in that Department during September 21-24. The main purpose of the conference, believed to be the first on this subject to be held in Britain, was to give ample opportunities for the discussion of network problems, and the lectures and papers which were presented took up only one-half of the time of each session in order to permit this. efficiently employed in the technical college. Industry can offer another valuable service--that of taking in the full-time teacher for periods of refreshment in current practice. Local education authorities are empowered to release teachers for up to 12 months for industrial experience without loss of pension rights.

Since industrial firms supply the great majority of students, they must keep the college generally informed of their education requirements-qualitatively and quantitatively. They must keep the colleges informed of the latest developments in their specialized fields and of the needs to which the college can contribute. They must support the colleges in their activities and assist them in carrying out their job-. whether by loaning staff or equipment or giving them the benefit of their knowledge in the advisory or administrative fields. They must consult with them on all matters of joint interest and maintain a constant flow of information in both directions.

The conference was attended by 140 representatives of education and industry from north-west England.

\section{IN ELECTRICAL ENGINEERING}

In a limited space it is not possible to give equal treatment to every paper and discussion, but it is hoped that the nature of some of the problems discussed will be made clear by the following account.

Of all the sessions, the first was the most fundamental and abstract but also at the greatest remove from any immediate relevance to practical problems. Mr. P. R. Bryant (General Electric Co., Wembley) spoke on a topological analysis of the order of complexity of an electrical network. The "order of complexity' was defined as the number of the natural frequencies of an electrical network and this number was shown to be equal to the number of dynamically independent network variables. In order to prevent too naïve an approach to this work it is only necessary to point out that a network of $n$ capacitors connected in series possesses an 'order of complexity' of $n$, whereas the network formed by connecting the capacitors in parallel is of order. 1. The other paper in this session was presented by Dr. V. Beleviteh (C.E.C.E., Brussels) and was concerned with a treat. ment by matrix algebra of the realizability theory for general linear, stable networks with $n$ terminalpairs.

A discussion on a group of papers on networks with parameters varying with time was opened by the authors-Prof. D. G. Tucker, Mr. D. P. Howson and Mr. J. M. Layton (University of Birmingham). A major part of the discussion centred on the possibility of applying, to networks with parameters varying with time, theorems developed from a study of networks with constant parameters. That care is needed in making translations of this kind was shown by a demonstration in one of the papers that the input: impedance of certain rectifier modulators was dependent on the nature and magnitude of the impedance associated with the source used to provide the input voltage and current. This result is more surprising than the discovery that theorems such as those of Thévenin and Norton cannot usefully be applied to many networks varying with time. Much more work is required to define the types of networks to which the main results of classical theory may be applied, 